\title{
Analysis on Influencing Factors of Self-Rated Health of Elderly Migrants
}

\author{
Zheng Shi \\ School of Government \\ Beijing Normal University \\ Beijing, China 100875
}

\begin{abstract}
Based on the 2017 National Dynamic Monitoring and Survey of Floating Population, this paper makes a quantitative analysis on the influencing factors of elderly migrants' self-rated health by means of binary logistic regression model. Results suggest that: first, elderly migrants who are male, well-educated and young in age and have a non-agricultural household are more likely to have a better self-rated health; second, the health status of inter-provincial elderly migrants is significantly better than that of intra-provincial elderly migrants, which conforms to the hypothesis of "healthy migration effect" and "natural selection"; third, Elderly migrants who are from southeast developed areas, have enjoyed free physical examination services and have a high health literacy have a high probability of self-rated health; fourth, Demographic sociological characteristics, flowing characteristics, and health services not only solely influence self-rated health, but also perform a role in self-rated health as indirect variable.
\end{abstract}

Keywords-elderly migrants; flowing characteristics; health services; self-rated health

\section{INTRODUCTION}

By the end of 2018, China's floating population was around 241 million, accounting for about $17.3 \%$ of the total population, of which the number of people aged 60 or over had reached 249.5 million, accounting for about $17.9 \%$ of the total population. In recent years, the scale of elderly migrants has been expanding continuously due to such reasons as working and doing business, moving with family members, remote oldage care, and young migrants getting old locally. Compared with young migrants, the health status of elderly migrants is not optimistic and there are potential health risks on their body. Population aging is an inevitable trend of society development of human beings. Governments around the world have reached a consensus on "healthy aging", and their attitude towards population aging is more positive and optimistic, thus establishing a multi-dimensional system for the health care of the elderly. In order to better offer all-round health services for elderly migrants, it is necessary to understand their health status and its influencing factors.

\section{LITERATURE REVIEW}

Studies on elderly migrants in the existing literature mainly include life satisfaction (Jin Xiaoyi, Liu Yanjun, 2017) [1], mental health (Hu Jianjiang, et al, 2016) [2], social integration
(Hu Yaping, 2018; Zhou Hongyun, Hu Haoyu, 2017) [3-4], public health services (Hou Huili, Li Chunhua, 2019) [5], medical security (Liu Luchan, 2019; Xiao Zhouyan, Shi Zheng, 2015) [6-7], family care (Piao Meilan, Jin Huashan, 2019) [8], residence willing (Hou Jianming, Li Xiaogang, 2017) [9], etc. Some scholars have also conducted a comprehensive investigation on the health status of elderly migrants based on chronic diseases and individual characteristics (Song Quancheng, Zhang Qian, 2018) [10]. The concept of self-rated health (SRH) has been used to measure the health status of the elderly since it was proposed in the middle of last century. It is a subjective assessment of the elderly on their health status. The reliability of self-rated health for health assessment of the elderly has been proved by scholars at home and abroad. Among studies involving self-rated health of the elderly, scholars have put more emphasis on the health status of nonfloating elderly, (Jiang Xiangqun, et al, 2015; Zhang Wenjuan, Wang Dongjing, 2018) [11][12], and made in-depth studies on the health status of the elderly from the perspectives of gender, social integration, urban-rural differences, marital status and residence style, etc.

In a word, there are mainly the following several limitations in few literature about health status of elderly migrants, which provides space for further study. First, in terms of range of study, more attention is paid to the health status of elderly migrants in a certain region or city, rather than elderly migrants across China. Second, in the selection of self-rated health indicators, health literacy, health records, physical examination services and other health service factors are often ignored, while health services may have a greater impact on the health status of elderly migrants. Third, most scholars have been concerned about the impact of flowing characteristics on health status, but fail to mention the influence of place of domicile (migrant-sending area) on it. On account of habitual dependence on lifestyle and differences in growing environment, the migrant-sending area has a more remarkable impact than migrant-receiving area on health status of elderly migrants. Fourth, as far as research methods concerned, most scholars only study the effect of single variables on self-rated health, and the interaction effect or mediating effect among variables may also affect the self-rated health of elderly migrants. In view of this, based on data from 2017 National Dynamic Monitoring and Survey of Floating Population, it is necessary to increase the independent variables of health services and migrant-sending area, and use the binary logistic 
that "Do you rate your heath as healthy", and "rate health as healthy" was assigned as 1, and "rate health as unhealthy" was assigned as 0 . Three independent variables of demographic sociological characteristics, flowing characteristics, and health services were determined. Under the premise of controlling demographic sociological characteristics, the influence of flowing characteristics and health services on the health status of elderly migrants was emphatically investigated (See "Table I").

\section{A. Data Source and Variable Assignment}

The 2017 National Dynamic Monitoring and Survey of Floating Population was selected as data source. The objects of study were elderly migrants aged 60 and above, and 6,478 qualified samples were selected. The dependent variable was

TABLE I. VARIABle Assignment AND BASIC CharaCteristics Statistics $(\mathrm{N}=6,478)$

\begin{tabular}{|c|c|c|c|}
\hline Name of Variables & Variable Assignments & Mean Value & Standard Deviation \\
\hline Dependent variable & & - & - \\
\hline Do you rate your heath as healthy? & $1=$ Yes, $0=$ No & 0.81 & 0.390 \\
\hline Variable & & - & - \\
\hline $\begin{array}{ll}\begin{array}{l}\text { Demographic } \\
\text { characteristics }\end{array} & \text { sociological } \\
\end{array}$ & & - & - \\
\hline Gender & $1=$ Male, $0=$ Female (Control group) & 0.58 & 0.493 \\
\hline Age (years old) & $\begin{array}{l}1=65-69,2=70-74,3=75-79,4=80 \text { and above, } 0=60-64 \text { (Control } \\
\text { group) }\end{array}$ & 0.84 & 1.067 \\
\hline Nationality & $1=$ Han nationality, $0=$ Ethnic minority (Control group) & 0.91 & 0.284 \\
\hline Education level & $\begin{array}{l}\text { 1=Junior and senior high school degree (technical secondary } \\
\text { school degree), } 2=\text { Bachelor's degree or above, } 0=\text { Primary } \\
\text { school education or below (Control group) }\end{array}$ & 0.59 & 0.610 \\
\hline Household registration type & 1=Agricultural, $0=$ Non-agricultural (Control group) & 0.58 & 0.494 \\
\hline Marital status & 1=Non-divorced, $0=$ Others (Control group) & 0.84 & 0.366 \\
\hline $\begin{array}{l}\text { Are you a member of the } \\
\text { Communist Party of China? }\end{array}$ & $1=$ Yes, $0=$ No (Control group) & 0.15 & 0.353 \\
\hline Flowing characteristics & & - & - \\
\hline $\begin{array}{l}\text { Place of domicile (migrant-sending } \\
\text { area) }\end{array}$ & $\begin{array}{l}\text { 1=North China, 2=East China , 3=South Central China, } \\
\text { 4=Southwest China, 5=Northwest China, 0=Northeast China } \\
\text { (Control group) }\end{array}$ & 2.28 & 1.727 \\
\hline $\begin{array}{l}\text { Are you an inter-provincial } \\
\text { migrant? }\end{array}$ & $1=$ Intra-province, $0=$ Outside the province $($ Control group $)$ & 0.55 & 0.497 \\
\hline Migrant-receiving areas & $\begin{array}{l}\text { 1=North China, 2=East China , 3=South Central China, } \\
\text { 4=Southwest China, 5=Northwest China, 0=Northeast China } \\
\text { (Control group) }\end{array}$ & 2.24 & 1.728 \\
\hline Health services & & - & - \\
\hline $\begin{array}{l}\text { Do you understand China's basic } \\
\text { public health policy? }\end{array}$ & $1=$ Yes, $0=$ No (Control group) & 0.57 & 0.496 \\
\hline $\begin{array}{l}\text { Have you been ill or unwell in the } \\
\text { last year? }\end{array}$ & $1=$ Yes, $0=$ No (Control group) & 0.53 & 0.499 \\
\hline $\begin{array}{l}\text { Have you ever enjoyed a physical } \\
\text { examination? }\end{array}$ & $1=$ Yes, $0=$ No (Control group) & 0.46 & 0.498 \\
\hline Do you have health records? & $1=$ Yes, $0=$ No (Control group) & 0.31 & 0.463 \\
\hline
\end{tabular}

a. Data from: 2017 National Dynamic Monitoring and Survey of Floating Population, the same as below.

\section{B. Model Construction and Test}

The selected dependent variable was "Do you rate your health as healthy?", including two results, namely, "Yes" and "No", which met the application conditions of binary logistic regression model. The dependent variable $(\mathrm{y})$ was either 0 or 1 . If $\mathrm{p}=\mathrm{P}(\mathrm{y}=1 \mid \mathrm{x}), 1-\mathrm{p}=\mathrm{P}(\mathrm{y}=0 \mid \mathrm{x})$.

Basic binary logistic model:

$$
\mathrm{P}(\mathrm{y}=1 \mid \mathrm{x})=\frac{\exp \left(x^{\prime} \beta\right)}{1+\exp \left(x^{\prime} \beta\right)}
$$

That is, $\operatorname{logit}(\mathrm{p})=\ln \left(\frac{p}{1-p}\right)=x^{\prime} \beta=\alpha+\mathrm{b} 1 \times 1+\mathrm{b} 2 \times 2+$ b3 $31 \times 2+\ldots+$ bpxp $+u$
Where, $x 1 \ldots x p$ respectively represent explanatory variables of age, gender, education level, etc., and $\alpha$ and $b$ represent parameters to be estimated, and $\mathrm{x} 1 \mathrm{x} 2$ represents interaction item, and $u$ represents disturbing item. $\mathrm{p}$ represents probability of "rating health as healthy", and 1-p represents probability of "rating health as unhealthy", $\mathrm{p} / 1-\mathrm{p}=\mathrm{OR}$. The collinearity test shows that the variance inflation coefficient of the independent variable is between [1.01, 3.82], less than the critical value of 10 , and the tolerance is between $[0.26,1.00]$, greater than the critical value of 0.1 , and the characteristic value is between $[0.03,8.47]$, not equal to 0 , and the condition index is between $[1.00,16.27]$, significantly less than the critical value of 30 . The independent variables are independent and there is no serious collinearity problem. 
different age groups. The proportion of elderly migrants who rated their health as healthy was higher, but the proportion decreased as their age increased. The proportion of Han nationality who rated their health as healthy was slightly higher than that of ethnic minority. The higher the education level, the higher the proportion of elderly migrants who rated their health as healthy. The proportion of the self-rated health of elderly migrants who have non-agricultural household is high. The health status of married elderly migrants was better than that of unmarried ones. Elderly migrants who were Party members had a better self-rated health compared with those who were non-Party members.

TABlE II. Cross-Statistics of Self-Rated Health Status of Elderly Migrants ( $\mathrm{N}=6,478$, Unit: \%)

\begin{tabular}{|c|c|c|c|c|}
\hline Independent Variables & Description Items & $\begin{array}{c}\text { Rating Their } \\
\text { Health as Healthy }\end{array}$ & $\begin{array}{c}\text { Rating Their } \\
\text { Health as } \\
\text { Unhealthy }\end{array}$ & $\chi^{2}$ (Sig) \\
\hline \multirow{2}{*}{ Gender } & Female & 77.4 & 22.6 & \multirow{2}{*}{$45.680 * * *$} \\
\hline & Male & 84.0 & 16.0 & \\
\hline \multirow{5}{*}{ Age } & $60-64$ & 86.1 & 13.9 & \multirow{5}{*}{$157.010 * * *$} \\
\hline & $64-69$ & 80.0 & 20.0 & \\
\hline & $70-74$ & 75.8 & 24.2 & \\
\hline & $75-79$ & 67.8 & 32.3 & \\
\hline & 80 and above & 63.8 & 36.2 & \\
\hline \multirow{2}{*}{ Nationality } & Ethnic minority & 78.1 & 21.9 & \multirow{2}{*}{$3.922^{*}$} \\
\hline & Han nationality & 81.6 & 18.4 & \\
\hline \multirow{3}{*}{ Education level } & Bachelor's degree or above & 90.9 & 9.1 & \multirow{3}{*}{$147.115^{* * *}$} \\
\hline & High school degree & 86.2 & 13.8 & \\
\hline & Primary school education or below & 75.2 & 24.8 & \\
\hline \multirow{2}{*}{ Household registration type } & Non-agricultural & 85.5 & 14.5 & \multirow{2}{*}{$56.974 * * *$} \\
\hline & Agricultural & 78.1 & 21.9 & \\
\hline \multirow{2}{*}{ Marital status } & Others & 77.5 & 22.5 & \multirow{2}{*}{$11.507 * *$} \\
\hline & Non-divorced & 82.0 & 18.0 & \\
\hline \multirow{2}{*}{ Are you a Party member? } & No & 80.3 & 19.7 & \multirow{2}{*}{$20.967 * * *$} \\
\hline & Yes & 86.6 & 13.4 & \\
\hline \multirow{2}{*}{ Are you an inter-provincial migrant? } & Outside the province & 84.6 & 15.4 & \multirow{2}{*}{$38.237 * * *$} \\
\hline & Intra-province & 78.6 & 21.4 & \\
\hline \multirow{4}{*}{ Migrant-receiving areas } & Northeast China & 74.5 & 25.5 & \multirow{6}{*}{$92.149 * * *$} \\
\hline & North China & 81.5 & 18.5 & \\
\hline & East China & 87.6 & 12.4 & \\
\hline & South Central China & 85.8 & 14.2 & \\
\hline \multirow{8}{*}{ Place of domicile (migrant-sending areas) } & Southwest China & 84.0 & 16.0 & \\
\hline & Northwest China & 76.5 & 23.5 & \\
\hline & Northeast China & 76.3 & 23.7 & \multirow{6}{*}{$89.098 * * *$} \\
\hline & North China & 78.8 & 21.2 & \\
\hline & East China & 88.4 & 11.6 & \\
\hline & South Central China & 85.6 & 14.4 & \\
\hline & Southwest China & 83.0 & 17.0 & \\
\hline & Northwest China & 76.1 & 23.9 & \\
\hline \multirow{2}{*}{ Do you understand public health policy? } & Yes & 82.8 & 17.2 & \multirow{2}{*}{$12.492 * * *$} \\
\hline & No & 79.3 & 20.7 & \\
\hline \multirow[t]{2}{*}{ Have you been ill or unwell in the last year? } & Yes & 73.5 & 26.5 & \multirow{2}{*}{$292.285^{* * *}$} \\
\hline & No & 90.1 & 9.9 & \\
\hline \multirow{2}{*}{ Have you ever enjoyed a physical examination? } & Yes & 72.1 & 27.9 & \multirow{2}{*}{$4.391 *$} \\
\hline & No & 68.1 & 31.9 & \\
\hline Do you have health records? & Yes & 79.8 & 20.2 & $-4.084 *$ \\
\hline & No & 81.9 & 18.1 & 4.084 \\
\hline
\end{tabular}

Second, the health status of elderly migrants outside the province was better than that of elderly migrants inside the province. The flow space distance had a "natural selection" effect on the health of the elderly. In terms of migrantreceiving areas, physical condition of the elderly flowing into northeast China was worse than that of the elderly flowing into the east China. On the whole, the proportion of elderly migrants who rated their health as healthy in the developed areas was higher. From the place of domicile (migrant-sending areas), the elderly from northwest, northeast and north China had a worse self-rated health than those from east, central south and southwest China. Generally speaking, the elderly from the 
north were in poor health, and those from the southeast were in good health.

Third, elderly migrants who understood the basic public health policy had a better self-rated health than those who did not understand the policy. Health literacy (cognition) affected the health status of elderly migrants. The proportion of selfrated health of elderly migrants who had been sick or unwell in the last year was relatively low. Elderly migrants who had enjoyed free physical examinations were in good health, while those who had not enjoyed free physical examinations were in poor health. The proportion of self-rated health of elderly migrants who had not established health records was higher than that of elderly migrants who had established health records.

\section{REGRESSION ANALYSIS OF INFLUENCING FACTORS OF SELF-RATED HEALTH OF ELDERLY MigRANTS}

Seven binary Logistic regression models were constructed, and demographic sociological characteristics were set as control variable (Model 1). On this basis, flowing characteristics (Model 2) and health services (Model 3) were added successively to investigate the influence degree of flowing characteristics and health services on self-rated health. Model 4 examined the influence degree of two interaction items of age*gender, and age*inter-provincial flowing on selfassessed health. In order to investigate fitting degree and robustness of the model, demographic sociological characteristics, flowing characteristics and health services were all included in the model (Model 5) to make regression analysis on self-rated health of rural elderly migrants (Model 6) and urban elderly migrants (Model 7). Results suggested that the proportion of regression models explaining the dependent variable increased from $8.2 \%$ to $18.7 \%$, and the overall percentage of the model was greater than $70 \%$. Regression models had a good fitting effect and could explain the dependent variable well.

Model 1 explained the influence degree of demographic sociological characteristics of elderly migrants on their selfrated health. Gender, age, household registration type and education level significantly affected self-rated health status, while nationality, political status and marital status had no significant influence on self-rated health. From the perspective of gender difference, probability of male elderly migrants who rated their health as healthy was 1.480 times that of female elderly migrants, so male elderly migrants' health status was more optimistic. In terms of age structure, age had a significant negative effect on the self-rated health status of elderly migrants. Compared with the age group from 60 to 64 years old, the probability of elderly migrants aged 65 and the above four age groups who rated their health as healthy decreased by $37.5 \%, 51.9 \%, 69.4 \%$ and $73.2 \%$ for each increasing age. Generally, the probability of elderly migrants who rated their health as healthy decreased as their age increased, and the oldest old were least likely to be healthy. As far as education level concerned, elderly migrants with bachelor's degree or above had the highest probability of self-rated health, while those with primary school degree or below had a low probability of self-rated health. It could be seen that education level had a significant impact on the health status of elderly migrants. Elderly migrants with higher education background had better jobs and salary before retirement, avoiding the health loss caused by heavy physical work. As for household registration type, the probability of self-rated health of elderly migrants with non-agricultural household was high, which was because they had a higher level of income and were more likely to get better health care services.

Model 2 explained the influence degree of flowing characteristics of elderly migrants on their self-rated health. Whether elderly migrants moved across provinces significantly affected the self-rated health status. The probability of interprovincial elderly migrants who rated their health as healthy was higher than that of intra-provincial elderly migrants. The flowing space distance was in direct proportion to the health status of the elderly. The better the physical status of the elderly, the more likely they were to move across provinces. On the contrary, they were predisposed to move within the province. The health status of elderly migrants is consistent with the hypothesis of "healthy migration effect", that is, the better the health status is, the stronger the flow will is. From the perspective of migrant-receiving areas, the probability of elderly migrants in north China, central south China and southwest China who rated their health as healthy was 1.381 , 1.546 and 1.695 times that of those in northeast China respectively. Geographical factors and economic development level affected the health status of elderly migrants. From the perspective of the domicile place (migrant-sending areas) of elderly migrants, the probability of elderly migrants from east China was 1.908 times that of those in northeast China. The economic development level and medical services of migrantsending areas obviously affected the health status of elderly migrants. Migrant-sending areas had a more significant influence on the health of elderly migrants than migrantreceiving areas. Their growth environment and genetic factors had a long-term and dominant impact on their health status.

Model 3 explained the influence degree of health services on the self-rated health of elderly migrants. Their health literacy, illness or discomfort in the last year, free physical examination and health record establishment significantly affected their self-rated health status. Elderly migrants with higher health literacy were more likely to have a better selfrated health. Knowing national public health policy can both avoid health resource waste and improve the health of elderly migrants. Elderly migrants who had been sick or unwell in the past year had a low probability of self-rated health. Most elderly migrants suffered from chronic diseases, and it was difficult for them to get better in a short period of time. It was particularly necessary for elderly migrants to get timely treatment after they got sick. Elderly migrants who had enjoyed national free physical examination services had a higher probability of self-rated health, and those who had not established a health file also had a higher probability of selfrated health. (See "Table III") 


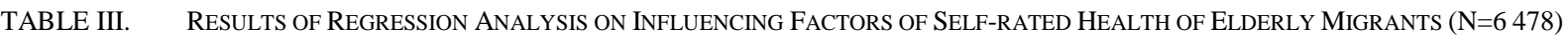

\begin{tabular}{|c|c|c|c|c|c|c|c|}
\hline Independent Variable & Model 1 & Model 2 & Model 3 & Model 4 & Model 5 & Model 6 & Model 7 \\
\hline \multicolumn{8}{|l|}{ Gender (Female) } \\
\hline Male & $1.480 * * *$ & $1.439 * * *$ & $1.459 * * *$ & $6.020 *$ & $1.423 * *$ & $1.770 * * *$ & 1.152 \\
\hline \multicolumn{8}{|l|}{ Age (60-64) } \\
\hline $65-69$ & $-0.625 * * *$ & $-0.622 * * *$ & $-0.585 * * *$ & $-0.664 * * *$ & $-0.577 * * *$ & $-0.518 * * *$ & $-0.645^{*}$ \\
\hline $70-74$ & $-0.481 * * *$ & $-0.513 * * *$ & $-0.592 * * *$ & $-0.557 * * *$ & $-0.622 * *$ & $-0.709+$ & $-0.550 *$ \\
\hline $75-79$ & $-0.306^{* * * *}$ & $-0.331 * * *$ & $-0.427 * * *$ & $-0.385 * * *$ & $-0.455 * * *$ & $-0.353 * * *$ & $-0.609+$ \\
\hline 80 and above & $-0.268 * * *$ & $-0.282 * * *$ & $-0.467 * * *$ & $-0.379 * * *$ & $-0.498 * *$ & $-0.328 * *$ & -0.764 \\
\hline \multicolumn{8}{|l|}{ Nationality (Ethnic minority) } \\
\hline Han nationality & 1.182 & 1.008 & $1.396^{*}$ & 1.105 & 1.113 & 1.142 & 1.072 \\
\hline \multicolumn{8}{|l|}{$\begin{array}{lll}\begin{array}{l}\text { Education level (Primary } \\
\text { education or below) }\end{array} & \text { school } \\
\end{array}$} \\
\hline $\begin{array}{l}\text { Junior and senior high school degree } \\
\text { (technical secondary school degree) }\end{array}$ & $1.553 * * *$ & $1.619 * * *$ & $1.269^{*}$ & $1.527 * * *$ & $1.347^{*}$ & 1.152 & $1.525^{*}$ \\
\hline Bachelor's degree or above & $2.283 * * *$ & $2.214 * * *$ & $2.748 * * *$ & $2.098 * * *$ & $2.671 * * *$ & -0.266 & $3.446^{* * * *}$ \\
\hline \multicolumn{8}{|c|}{$\begin{array}{l}\begin{array}{l}\text { Household registration type (Non- } \\
\text { agricultural) }\end{array} \\
\end{array}$} \\
\hline Agricultural & $-0.682 * * *$ & $-0.651 * * *$ & $-0.879 * * *$ & $-0.678^{* * *}$ & $-0.851 * * *$ & - & - \\
\hline \multicolumn{8}{|l|}{ Marital status (Others) } \\
\hline Non-divorced & -0.986 & -0.922 & -0.942 & -0.911 & -0.958 & -0.944 & 1.166 \\
\hline \multicolumn{8}{|l|}{ Politics status (Non-Party member) } \\
\hline Party member & 1.123 & 1.055 & 1.241 & 1.137 & 1.123 & $1.944 *$ & -0.909 \\
\hline \multicolumn{8}{|l|}{$\begin{array}{l}\text { Inter-provincial flowing or not (Outside } \\
\text { the province) }\end{array}$} \\
\hline Intra-province & & $-0.722 * * * *$ & & & -0.956 & -0.968 & -0.916 \\
\hline \multicolumn{8}{|l|}{$\begin{array}{l}\text { Migrant-receiving areas } \text { (Northeast } \\
\text { China) }\end{array}$} \\
\hline North China & & $1.381^{*}$ & & & $1.567 *$ & -0.946 & $2.200^{*}$ \\
\hline East China & & 1.349 & & & 1.481 & 1.676 & 1.068 \\
\hline South Central China & & $1.546^{*}$ & & & 1.106 & 1.349 & -0.819 \\
\hline Southwest China & & $1.695^{*}$ & & & 1.381 & 1.212 & 1.338 \\
\hline Northwest China & & 1.227 & & & 1.207 & -0.680 & $2.287+$ \\
\hline \multicolumn{8}{|l|}{ Place of domicile (Northeast China) } \\
\hline North China & & -0.950 & & & -0.976 & 1.598 & -0.722 \\
\hline East China & & $1.908^{* * *}$ & & & $2.003^{*}$ & $2.285^{*}$ & $1.959+$ \\
\hline South Central China & & 1.308 & & & $1.634+$ & 1.722 & 1.862 \\
\hline Southwest China & & 1.198 & & & 1.521 & 2.060 & 1.307 \\
\hline Northwest China & & 1.015 & & & 1.072 & 1.595 & -0.793 \\
\hline \multicolumn{8}{|l|}{$\begin{array}{l}\text { Do you understand public health } \\
\text { policy? (No) }\end{array}$} \\
\hline Yes & & & $1.303^{*}$ & & $1.271^{*}$ & 1.099 & $1.396+$ \\
\hline \multicolumn{8}{|l|}{$\begin{array}{l}\text { Have you been ill or unwell in the last } \\
\text { year? (No) }\end{array}$} \\
\hline Yes & & & $-0.371 * * *$ & & $-0.361 * * *$ & $-0.366^{* * * *}$ & $-0.308 * * *$ \\
\hline \multicolumn{8}{|l|}{$\begin{array}{l}\text { Have you ever enjoyed a physical } \\
\text { examination? (No) }\end{array}$} \\
\hline Yes & & & $1.460^{* * *}$ & & $1.412 * * *$ & $1.399 *$ & $1.518^{*}$ \\
\hline \multicolumn{8}{|l|}{ Do you have health records? (No) } \\
\hline Yes & & & $-0.650 * *$ & & $-0.719 *$ & 0.842 & $-0.625^{*}$ \\
\hline \multicolumn{8}{|l|}{ Interaction items } \\
\hline Age*inter-provincial flowing & & & & $-0.995 * * *$ & - & - & - \\
\hline Age*gender & & & & $-0.979 *$ & - & - & - \\
\hline Cox\&snell R2 & 0.051 & 0.068 & 0.104 & 0.054 & 0.123 & 0.136 & 0.111 \\
\hline Nagelkerke R2 & 0.082 & 0.111 & 0.147 & 0.088 & 0.175 & 0.187 & 0.166 \\
\hline Overall Percentage & $81.3 \%$ & $81.4 \%$ & $71.8 \%$ & $81.3 \%$ & $72.6 \%$ & $71.4 \%$ & $77.5 \%$ \\
\hline Constant & $4.817 * * *$ & $4.222 * * *$ & $3.261 * * *$ & $5.708 * * *$ & $2.836^{* * * *}$ & 1.729 & $2.763 *$ \\
\hline
\end{tabular}

Under the premise of controlling demographic sociological characteristics, Model 4 investigated the influence degree of interaction items of age*gender and age* inter-provincial flowing on self-rated health. Results showed that the two groups of interaction items exerted a significant negative effect on self-rated health and self-rated health was affected by the interaction between variables. In order to further investigate whether there is an indirect effect between age and interprovincial flowing, stratified regression method was used to test it (See "Table IV"). Results indicated that there was a "partial mediating effect", that is, age had a partial effect on self-rated health through inter-provincial flow. The purpose of the interaction effect and indirect effect test is to verify that demographic sociological characteristics, flowing characteristics and health services do not solely affect selfrated health, and this is the result of interaction among them. Model 5 included demographic sociological characteristics, flowing characteristics and health services into it. Except 
variables, the influence degree of most of variables had no significant change, which proved that the regression model had a good robustness. whether the influence degree of inter-provincial flowing decreased, the influence degree of other variables changed little. In Model 6 and Model 7, apart from the increase or decrease of the influence degree of individual variables on dependent

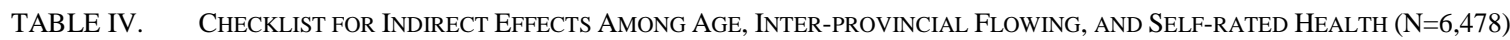

\begin{tabular}{|c|c|c|c|c|c|c|c|}
\hline Models & $\begin{array}{l}\text { Dependent } \\
\text { Variables }\end{array}$ & Independent Variables & $\mathbf{R 2}$ & $B$ value & $\begin{array}{l}\text { Standard } \\
\text { Error }\end{array}$ & T value & Sig value \\
\hline Model 4-1 & Self-rated health & Age & 0.024 & -0.155 & 0.004 & -12.633 & $* * *$ \\
\hline Model 4-2 & $\begin{array}{l}\text { Inter-provincial } \\
\text { flowing }\end{array}$ & Age & 0.002 & 0.042 & 0.006 & 3.392 & $* *$ \\
\hline \multirow{2}{*}{ Model 4-3 } & \multirow{2}{*}{ Self-rated health } & Age & \multirow{2}{*}{0.029} & -0.152 & 0.004 & -12.411 & $* * *$ \\
\hline & & Inter-provincial flowing & & -0.070 & 0.010 & -5.746 & $* * *$ \\
\hline
\end{tabular}

\section{CONCLUSION}

First, elderly migrants are male, well-educated and young in age and have a non-agricultural household are more likely to have a better self-rated health. The influence degree of marital status, Party membership and nationality on self-rated health is not obvious. Second, the probability of elderly migrants from more developed areas and the southeast who rate their health as healthy is high. Migrant-sending areas have a more significant impact on their self-rated health. The flowing space distance is highly correlated with the health status of elderly migrants, and older people with better physical condition are predispose to move across provinces, while older people with poor physical condition are more likely to move in the province, which conforms to the theory of "healthy migration effect" and "natural selection". Third, elderly migrants who have enjoyed free physical examination services, high health literacy and have not been ill or unwell in the past year have a high probability of self-rated health. Fourth, demographic sociological characteristics, flowing characteristics, and health services not only solely influence self-rated health, but also perform a role in self-rated health as indirect variable.

\section{REFERENCES}

[1] Jin Xiaoyi, Liu Yanjun. Impact of Caring for Grandchildren on Life Satisfaction of the Elderly - A Study Based on Migrant Elderly and NonMigrant Elderly [J]. Journal of Southeast University (Philosophy and Social Science), 2017, 19 (02): 119-129+148. (in Chinese)

[2] Hu Jianjiang, Ni Yanyan, Li Qiuju, et al. Depression among Elderly Migrants in Urban Hangzhou: A Cross-sectional Study [J]. Chinese Journal of Public Health, 2016, 32 (09): 1144-1148. (in Chinese)

[3] Hu Yaping, Liu Yue, Wang Chengkuan. Research on the Influencing Factors of the Elder Immigrants' Social Integration [J]. Population \& Economics, 2018 (06): 77-88. (in Chinese)

[4] Zhou Hongyun, Hu Haoyu. Influence of Social Support on Social Integration of Elderly Migrants: Based on the Survey Data in Wuhan and Shenzhen [J]. Northwest Population Journal, 2017, 38 (04): 24-32. (in Chinese)

[5] Hou Huili, Li Chunhua. Identity, Region and City Size: Inequality of Basic Public Health Services for the Elderly Floating Population [J]. Population and Development, 2019, 25 (02): 31-38. (in Chinese)

[6] Liu Luchan. Elderly Migrants with Hospitalization in Other Places Behavior Characteristics, Support System and System Guarantee [J]. Journal of Nanjing College for Population Programme Management, 2019, 35 (01): 39-51. (in Chinese)

[7] Xiao Zhouyan, Shi Zheng. Chinese Off-Site Medical Dilemma and Path Optimization Research [J]. Jianghan Academic, 2015, 34 (03): 19-24. (in Chinese)
[8] Piao Meilan, Jin Huashan. Demand and Plight of the Care Services for Elderly Korean Women from the Perspective of Cross-regional Mobility [J]. Journal of Yunnan Nationalities University (Social Sciences Edition), 2019, 36 (01): 123-128. (in Chinese)

[9] Hou Jianming, Li Xiaogang. The Analysis of the Status of China's Floating Elderly Population and It's Influencing Factors [J]. Population Journal, 2017, 39 (06): 62-70. (in Chinese)

[10] Song Quancheng, Zhang Qian. A Study on the Health Status and Influencing Factors of Elderly Migrants in China [J]. Chinese Journal of Population Science, 2018 (04): 81-92+127-128. (in Chinese)

[11] Jiang Xiangqun, Wei Meng, Zhang Wenjuan. Study on the Health Status and Influencing Factors of China's Aging Population [J]. Population Journal,2015, 37 (02): 46-56. (in Chinese)

[12] Zhang Wenjuan, Wang Dongjing. The Health Status and Its Changes of the Chinese Elderly [J]. Population \& Economics, 2018 (04): 86-98. (in Chinese) 